\title{
Effect of Oxytocin Injection into Umbilical Vein for Management of Retained Placenta
}

\author{
Lima Shompa ${ }^{1}$, Sayeba Akhter ${ }^{2}$, Khadija Nazneen ${ }^{3}$, Monnujan Begum ${ }^{4}$ \\ Received: December 11, 2013 Accepted: April 12, 2014
}

\begin{abstract}
Background: Retained placenta is one of the causes of post-partum hemorrhage in Bangladesh as it is worldwide. If a retained placenta is left untreated, there is a high risk of maternal morbidity and mortality and it has inherent risks of infection and hemorrhage. Manual removal of placenta which is the recommended treatment of retained placenta usually requires regional or general anesthesia. Intraumbilical injection of saline solution with oxytocin might represent an important option for management of retained placenta. Objectives: The aim of this study was to assess the effect of intraumbilical vein oxytocin in the management of retained placenta and to compare it to the risk of manual removal of placenta. Materials and Methods: This experimental study was conducted in the department of Obstetrics and Gynecology in Dhaka Medical College \& Hospital during July to December 2004. Total 50 patients with retained placenta were included in this study. The patients were divided purposively randomly into two groups - Groups A and B. Twenty patients in Group A were managed by intraumbilical vein injection of 10 units of oxytocin in $20 \mathrm{~mL}$ of normal saline slowly and 30 patients in Group $B$ were managed by manual removal of placenta. Results: Among the patients of Group A, 16 (80\%) delivered placenta spontaneously with expulsion time of 7-12 minutes. Remaining 4 patients (20\%) required manual removal of placenta even after intraumbilical vein injection of oxytocin. Group A patients had less complications, required less blood transfusion, less antibiotics and less hospital stay compared to Group B patients. Conclusion: Intraumbilical vein administration of oxytocin is superior to manual removal in the management of retained placenta.
\end{abstract}

Key words: Oxytocin; Intraumbilical vein; Retained placenta

J Enam Med Col 2014; 4(2): 102-105

\section{Introduction}

Placenta is said to be retained when it is not expelled out even 30 minutes after birth of the baby. ${ }^{1}$ Retained placental tissue and membrane causes $5-10 \%$ of post-partum hemorrhage $(\mathrm{PPH}){ }^{2}$ Worldwide, PPH remains one of the most common causes of maternal mortality. If a retained placenta is left untreated, there is a high risk of maternal death. Manual removal of placenta which is the

recommended treatment also carries other risks such as immediate trauma to uterus, hemorrhage and an increased incidence of puerperal infection. . $^{3,4}$

Retained placenta is potentially life-threatening not only because of retention but also because of associated hemorrhage and infection as well as complications related to its removal. ${ }^{4}$ There are now

1. Assistant Professor, Department of Obstetrics and Gynecology, Enam Medical College \& Hospital, Savar, Dhaka

2. Professor, Department of Obstetrics and Gynecology, Ad-din Medical College \& Hospital, Dhaka

3. Professor, Department of Obstetrics and Gynecology, Enam Medical College \& Hospital, Savar, Dhaka

4. Professor, Department of Obstetrics and Gynecology, Enam Medical College \& Hospital, Savar, Dhaka

Correspondence Lima Shompa, Email: lshompa@gmail.com 
evidences that manual removal of placenta may be a risk factor for infection ${ }^{3}$, post-partum endometritis and risk of increased bleeding by interfering with normal mechanism of placental separation. ${ }^{2}$

Routine administration of oxytocin during the third stage hastens placental separation, reduces blood loss of delivery and decreases the chance of $\mathrm{PPH}$ by $40 \% .^{2}$ Oxytocin is the first line agent because of the paucity of side effects compared with all other available agents. ${ }^{5}$

Umbilical vein injection of saline solution with oxytocin might represent an important option for management of retained placenta. This relatively simple and affordable technique could be used either for first response before proceeding to manual removal if necessary or as the only response where manual removal is not feasible. 6 This procedure facilitates high concentration of oxytocin to the placental bed and uterine wall, resulting in uterine contraction and placental separation. ${ }^{7}$

Intraumbilical vein injection (IUV) is inexpensive, non-surgical, non-aggressive, cheap and pharmacological method which may be included in the treatment of retained placenta before going to manual lysis of placenta. ${ }^{8}$

Regarding retained placenta, findings from international studies and clinical researches showed that appropriate and adequate management during emergency can reduce the mortality and long term complications. As there are very few numbers of studies done on retained placenta in Bangladesh, we designed this experimental study to assess the effect of intraumbilical vein oxytocin in the management of retained placenta and to compare it to the risk of manual removal of placenta.

\section{Materials and Methods}

This experimental study was conducted in labor ward in the department of Obstetrics and Gynecology in Dhaka Medical College Hospital (DMCH), Dhaka during the period July to December, 2004. Patients who had undergone vaginal delivery and failed to deliver placenta within 30 minutes of delivery of the baby and admitted with retained placenta irrespective of whether active management policy was followed or not were included. Patients having comorbidities along with retained placenta, having partial separation, morbid adhesion and retention of placenta for more than 24 hours, who presented with chorioamnionitis, complicated $1^{\text {st }}$ and $2^{\text {nd }}$ stage of labor and with abruption placenta were excluded. Study subjects were purposively randomly divided into two groups. Group A included 20 patients who were given intraumbilical vein oxytocin and Group $B$ included 30 patients who were managed with planned manual removal of placenta.

A solution of $10 \mathrm{~mL}$ oxytocin diluted in $20 \mathrm{~mL}$ normal saline $(0.9 \%$ sodium chloride) was injected into the umbilical vein in all patients of Group A after the umbilical cord was clamped distally. The umbilical vein injection was given over a period of 30 minutes and traction was avoided until there was evidence of placental separation. ${ }^{9}$ Suprapubic pressure was applied while observing for evidence of placental separation. No other intervention was performed to cause placental separation until at least 15 minutes after administration of oxytocin. After expulsion of the placenta oxytocin was administered as indicated.

Comparison between the groups was done by chisquare test using the SPSS version 16.0. $\mathrm{p}$ values $<0.05$ were considered significant.

\section{Results}

Total 8501 obstetric patients were admitted during the study period. Among them, number of patients having retained placenta was $175(2.05 \%)$. Out of 50 study subjects $32(64 \%)$ patients presented at 38 weeks of pregnancy and $15(30 \%)$ patients at 39 weeks. Majority of the patients $(38,76 \%)$ delivered babies at home. Only $8(16 \%)$ patients delivered in $\mathrm{DMCH}$. Delivery was conducted by dai or relatives in majority patients $(38,76 \%)$. About $62 \%$ patients were admitted with features of shock and 12 (24\%) had PPH without shock.

After administration of intraumbilical vein injection (IUV) of oxytocin in patients of Group A, placenta was delivered in $16(80 \%)$ cases. Four $(20 \%)$ cases required manual removal of placenta. Group B patients $(30,100 \%)$ were managed with planned manual removal of placenta.

Table I shows that in Group A, 5 (25\%) patients required one unit of blood transfusion, $4(20 \%)$ required two units, $4(20 \%)$ three units and $7(35 \%)$ 
patients did not require blood transfusion. In Group B, $6(20 \%)$ patients needed 4 units of blood transfusion, $8(26.66 \%)$ needed 3 units, $10(33.3 \%)$ required two units, $4(13.33 \%)$ required one unit and $2(6.6 \%)$ required no blood transfusion.

Table I: Units of blood transfusion per patient

\begin{tabular}{|l|c|c|c|c|}
\hline Units & $\begin{array}{c}\text { Group A } \\
(\mathrm{n}=20) \\
\text { Number }(\%)\end{array}$ & $\begin{array}{c}\text { Group B } \\
(\mathrm{n}=30)\end{array}$ & $\chi^{2}$ value & $\mathrm{p}$ value \\
\hline 0 & $7(35)$ & $2(6.6)$ & & \\
\hline 1 & $5(25)$ & $4(13.3)$ & & \\
\hline 2 & $4(20)$ & $10(33.3)$ & 11.24 & 0.024 \\
\hline 3 & $4(20)$ & $8(26.66)$ & & \\
\hline 4 & $0(0)$ & $6(20)$ & & \\
\hline & & & & \\
\hline
\end{tabular}

Table II shows that in Group A, duration of staying in hospital was $\leqslant 1$ day in $16(80 \%)$ patients and $2-4$ days in $4(20 \%)$ cases. In Group B, $8(26.66 \%)$ patients stayed in the hospital $\leqslant 1$ day, $20(66.66 \%)$ for 2-4 days and $2(6.66 \%)$ patients for 5-7 days. The duration of hospital stay was significantly less $(p=0.001)$ in oxytocin group.

Table II: Length of hospital stay

\begin{tabular}{|c|c|c|c|c|}
\hline Duration & $\begin{array}{c}\text { Group A } \\
(n=20) \\
\text { Number }(\%)\end{array}$ & $\begin{array}{c}\text { Group B } \\
(n=30) \\
\text { Number }(\%)\end{array}$ & $\chi^{2}$ value & $\mathrm{p}$ value \\
\hline$\leqslant 1$ day & $16(80)$ & $8(26.66)$ & & \\
\hline 2-4 days & $4(20)$ & $20(66.66)$ & 13.9 & 0.001 \\
\hline 5-7 days & $0(0)$ & $2(6.66)$ & & \\
\hline
\end{tabular}

Table III shows that in Group A, $16(80 \%)$ cases required no anesthesia or analgesia, $2(10 \%)$ required general anesthesia and $2(10 \%)$ needed sedative with analgesia. In Group B, 20 (66.66\%) patients required general anesthesia and $10(33.33 \%)$ cases required sedative with analgesia.

Table III: Types of anesthesia and/or analgesia used during removal of retained placenta

\begin{tabular}{|l|c|c|c|c|}
\hline Types & $\begin{array}{c}\text { Group A } \\
(\mathrm{n}=20) \\
\text { Number }(\%)\end{array}$ & $\begin{array}{c}\text { Group B } \\
(\mathrm{n}=30) \\
\text { Number (\%) }\end{array}$ & $\chi^{2}$ value & p value \\
\hline $\begin{array}{l}\text { Sedative with } \\
\text { analgesia }\end{array}$ & $2(10)$ & $10(33.33)$ & & \\
$\begin{array}{l}\text { General anesthesia } \\
\begin{array}{l}\text { No anesthesia or } \\
\text { analgesia }\end{array}\end{array}$ & $\begin{array}{c}2(10) \\
16(80)\end{array}$ & $\begin{array}{c}20(66.66) \\
0(0)\end{array}$ & 35.5 & 0.000 \\
\hline
\end{tabular}

Table IV shows the frequency and types of complications at or after removal of placenta. In Group A, $2(10 \%)$ cases developed PPH and 18 $(90 \%)$ cases had no complications. In Group B, 6 (20\%) cases developed PPH, and $4(13.33 \%)$ cases developed sepsis or endometritis.

Table IV: Frequency of complications at or after removal of retained placenta

\begin{tabular}{l|c|c|c|c} 
Complications & $\begin{array}{c}\text { Group A } \\
(\mathrm{n}=20) \\
\text { Number (\%) }\end{array}$ & $\begin{array}{c}\text { Group B } \\
(\mathrm{n}=30)\end{array}$ & $\chi^{2}$ value & $\mathrm{p}$ value \\
\hline PPH & $2(10)$ & $6(20)$ & & \\
$\begin{array}{l}\text { Sepsis or } \\
\text { endometritis }\end{array}$ & $0(0)$ & $4(13.33)$ & 4.28 & 0.118 \\
\hline No complications & $18(90)$ & $20(66.66)$ & & \\
& & &
\end{tabular}

Table $\mathrm{V}$ shows the use of antibiotics in study subjects. In Group A, $16(80 \%)$ patients required double antibiotics and $4(20 \%)$ cases required triple antibiotics. In Group B, 3 (10\%) cases needed double antibiotics and $27(90 \%)$ cases required triple antibiotics.

Table V: Frequency of use of antibiotics

\begin{tabular}{|l|c|c|c|c|}
\hline Antibiotics & $\begin{array}{c}\text { Group A } \\
(\mathrm{n}=20) \\
\text { Number }(\%)\end{array}$ & $\begin{array}{c}\text { Group B } \\
(\mathrm{n}=30)\end{array}$ & $\chi^{2}$ value & p value \\
\hline $\begin{array}{l}\text { Nouble }(\%) \\
\text { antibiotics }\end{array}$ & $16(80)$ & $3(10)$ & & \\
$\begin{array}{l}\text { Triple } \\
\text { antibiotics }\end{array}$ & $4(20)$ & $27(90)$ & & \\
\hline
\end{tabular}

\section{Discussion}

This study showed that during the period from January to December 2004 the incidence of retained placenta was $2.05 \%$ of total obstetric admission in $\mathrm{DMCH}$. In a study by Chhabra et $\mathrm{l}^{10}$ in Kasturba Hospital, Delhi, it was found that incidence of retained placenta was $0.23 \%$ of all births over 15 years. In their study, out of four deaths two women delivered at nearby district hospital and were referred moribund and died. The policy option was that the properly conducted delivery can reduce the incidence of retained placenta and if removal occurs timely, appropriate care can save life.

Regarding management of retained placenta the present study can be compared with a number of 
studies. In this study, $16(80 \%)$ patients of Group A, who were managed by intraumbilical vein injection of 10 units oxytocin in $20 \mathrm{~mL}$ normal saline, delivered placenta spontaneously with an expulsion time of 7 to 12 minutes after injection and $4(20 \%)$ patients required manual removal. Study done by Golan et $\mathrm{al}^{3}$ using the same methodology showed that expulsion of placenta occurred in all of their 10 cases a few minutes after intraumbilical injection. The average injection-expulsion time was 2-5 minutes. Using the proposed method of oxytocin injection into the umbilical cord of retained placenta they were able to spare $80 \%$ of the patients. A study done in department of Obstetrics and Gynecology, Liverpool Women's Hospital, United Kingdom revealed that women given an intraumbilical oxytocin injection had a significant increase in spontaneous expulsion of placenta within 45 minutes of delivery and fewer manual removal of placenta was needed. The result of their study suggested clinically important beneficial effect of intraumbilical oxytocin injection in the management of retained placenta. ${ }^{11}$ These findings are consistent with the present study.

In this study, requirement of blood transfusion was less in oxytocin group. This finding correlates with study done by Gajvani et al. ${ }^{11}$ A study done by Das $\mathrm{SR}^{12}$ shows that $23.31 \%$ cases needed general anesthesia while removing the placenta manually. In the present study, only $2(10 \%)$ patients in Group A required general anesthesia whereas in Group B, 20 $(66.66 \%)$ patients required general anesthesia. Patients of Group B required exploration of uterus and had to stay longer in hospital than patients of Group A.

In this study complications at or after management of retained placenta with intraumbilical vein injection of oxytocin was less than the non-oxytocin group. Among oxytocin group $18(90 \%)$ cases had no complications and $2(10 \%)$ cases developed PPH. In non-oxytocin group eight patients developed fever and sepsis after manual removal of placenta. The complications were very less in oxytocin group which correlates with the findings of study done by Golan et al. ${ }^{3}$

The present study reveals that intraumbilical oxytocin solution is superior to manual removal of placenta. As this study was done in a small number of patients, we recommend that community based study having adequate sample size should be carried out to find out further evidence of efficacy and feasibility of the method in low resource setting.

\section{References}

1. Dutta DC. Complications of the third stage of labour. In: Hiralal Konar (ed). Textbook of Obstetrics. $6^{\text {th }}$ edn. Calcutta: New Central Book Agency, 2004: 450-454.

2. Poggi SBH, Kapernick PS. Postpartum hemorrhage and the abnormal puerperium. In: Decherney AH, Nathan L (eds). Current obstetrics and gynecologic diagnosis \& treatment. 9th edn. New York: McGraw-Hill, 2003: 531-552.

3. Golan A, Lidor AL, Wexlers David MP. A new method for the management of retained placenta. Am J Obstet Gynecol 1983; 146: 708-709.

4. Carroli G, Bergel E. Umbilical vein injection for management of retained placenta. Cochrane database of systematic reviews 2001, Issue 4. Art. No. CD001337. DOI: 10.1002/14651858.CD001337.

5. van Dongen PW, van Roosmalen J, de Boer CN, van Rooy J. Oxytocics for the prevention of post-partum haemorrhages, a review. Pharm Weekbl Sci 1991; 13: 238-243

6. Purwar M. Injection umbilical vein for management of retained placenta commentary (17 Nov 2000) WHO Reproductive Health Library No. 4, Oxford update software.

7. Neri A, Goldman J, Ganj B. Intraumbilical vein injection of pitocin. A new method in the management of third stage of labour. Harefuah 1966; 70: 351-353.

8. Habeks D, Hrgovic Z, Ivanisevic M, Delmis J. Treatment of retained placenta with intraumbilical injection. Zentralbi-gynakol 2001; 123(7): 415-417.

9. David H, Chestnut MD. Influence of umbilical vein administration of oxytocin on $3^{\text {rd }}$ stage of labour: a randomized, double blind, placebo-controlled study. Am J Obstet Gynecol 1987; 157(1):160-162.

10. Chhabra S, Dhorey M. Retained placenta continues to be fatal but frequency can be reduced. Journal of Obstetrics and Gynecology 2002; 22(6): 630-633.

11. Gajvani MR, Luckus MJM, Drakeley AJ, Emery SJ, Alfirevic Z, Walkinshaw SA. Intraumbilical vein injection for the management of retained placenta; a randomized controlled trial. Obstet Gynecol 1998; 203-207.

12. Das SR. Incidence and causes of retained placenta of admitted cases in IPD of Dhaka Medical College Hospital. [FCPS Dissertation]. Dhaka: Bangladesh College of Physicians and Surgeons; 2003. 